\title{
A census and status review of the Endangered François' langur Trachypithecus francoisi in Chongqing, China
}

\author{
Zongxian Han, Gang Hu, Shaobin Wu, Changlei Cao and Xin Dong
}

\begin{abstract}
From September 2009 to September 2010 we undertook a survey of the Endangered François' langur Trachypithecus francoisi in south-east Chongqing to compare the species' present status with historical records from the 1990s. Based on a literature review, interviews with local people and our survey we found François' langurs in only three isolated sites, across four counties, with a total area of occurrence of c. $57 \mathrm{~km}^{2}$. The total population was estimated to be c. 200 individuals in 27 mixed sex groups. There were 21 groups (149 individuals) within a reserve (Jinfoshan), and four groups (36) in Furongiiang and two groups (13) in Heishangu were not within any reserve. The primary threat to the langur is habitat loss caused by traditional firewood use and agricultural encroachment but there is also increasing loss of forest to hydroelectric projects and construction of tourism infrastructure and facilities such as highways, hotels and telephone lines. The three sites in southern Chongqing province are adjacent to four areas in north-east Guizhou province that contain c. $60 \%$ of the wild population of the species in China. The seven sites combined are the main stronghold of this species and the geographical proximity of the sites raises the possibility of setting up ecological corridors between some of them.
\end{abstract}

Keywords Chongqing, François' langur, habitat degradation, isolated distribution, population size, Trachypithecus francoisi

\section{Introduction}

Trançois' langur Trachypithecus francoisi, categorized as Endangered on the IUCN Red List (Bleisch et al., 2008), is geographically widespread, ranging from the Red River in northern Vietnam to south-central China (Fooden, 1996; Groves, 2001; Zhang et al., 2002). Wild populations of this species occur in fragmented forest habitats scattered across

ZongXian Han*, Shaobin Wu and Changlei CaO School of Life Science and Technology, Yangtze Normal University, Fuling, Chongqing, China

GANG $\mathrm{HU}^{*}$ (Corresponding author) and XIN DoNG Institute of Rare Wildlife, China West Normal University, Nanchong, Sichuan, China, and Kay Laboratory of Southwest China Wildlife Resources Conservation, Educational Ministry of China, Nanchong, Sichuan, China. E-mail ganghu126@126.com

*ZONGXIAN HAN and GaNG Hu contributed equally to this paper

Received 3 March 2011. Revision requested 16 May 2011.

Accepted 19 July 2011. its range $(\mathrm{Hu}, 2007)$. In China the available data indicate that François' langurs were historically reported from 27 sites in 23 counties in Guangxi, 12 sites (nine counties) in Guizhou and two sites (three counties) in Chongqing, with a total population of c. 3,500 in the 1990s (Wu et al., 1987; Li et al., 1994; Tang \& Zhang, 1994, 1998; Liu \& Wei, 1995; Su et al., 2002).

During the past 2 decades a dramatic population decline, attributed largely to hunting, has been documented in Guangxi (Hu \& Wei, 2002; Hu et al., 2004) and North Vietnam (Nadler et al., 2003), with the population estimated at c. 300 each in Guangxi (Li et al., 2007) and North Vietnam (Nadler et al., 2003). In Guizhou, however, hunting pressure is generally slight and the population increased from 1,000 in the 1990 s ( $\mathrm{Li}, 1995)$ to $1,160-1,200$ in 2010 , although the species has been extirpated from several sites and is now restricted to just five isolated fragments because of extensive human disturbance ( $\mathrm{Hu}$ et al., 2011).

There is little information available on the population size and distribution of François' langur in Chongqing. There are two reports based on surveys conducted in the 1990 s that documented c. 80 individuals in seven groups in Jinfoshan (Tang \& Zhang, 1994, 1998) and 40-45 individuals in four groups in Furongjiang ( $\mathrm{Su}$ et al., 2002). The aim of the survey reported here was to assess the current distribution and population of, and the threats to, François' langurs in Chongqing, to provide the basis for a management plan.

\section{Methods}

We reviewed relevant literature, including published articles and unpublished reports, to obtain historical information on the distribution and population of François' langur. We then conducted interviews with staff of local forestry agencies and reserves, hunters and village elders at sites where François' langur was known to occur historically. In the interviews we gathered information about the latest date of direct observations and data on locations and group sizes. We randomly interviewed other villagers and staff to reaffirm the findings. Based on this interview information we chose six sites where langurs were recorded in the 1990 s to conduct a 1-month preliminary survey 5 days at each site). During the preliminary survey we found no langurs or traces of fresh faeces at three sites (Simianshan, Wanzu and Gongtan) and so excluded these from more detailed surveys. 
The three further sites (Jinfoshan, Furongjiang and Heishangu) covered four counties in south and south-east Chongqing (Fig. 1). These areas have a subtropical monsoon climate (Han \& Hu, 2010; Table 1). The landscape is dominated by limestone mountains with steep valleys and gentle limestone plateaus at $200-2,250 \mathrm{~m}$ altitude. Vegetation composition varies depending on the degree of human impact but the main vegetation types are subtropical evergreen broadleaf forest at low altitudes and mixed deciduous-coniferous forest at higher altitudes (Tang \& Zhang, 1998; Su et al., 2002).

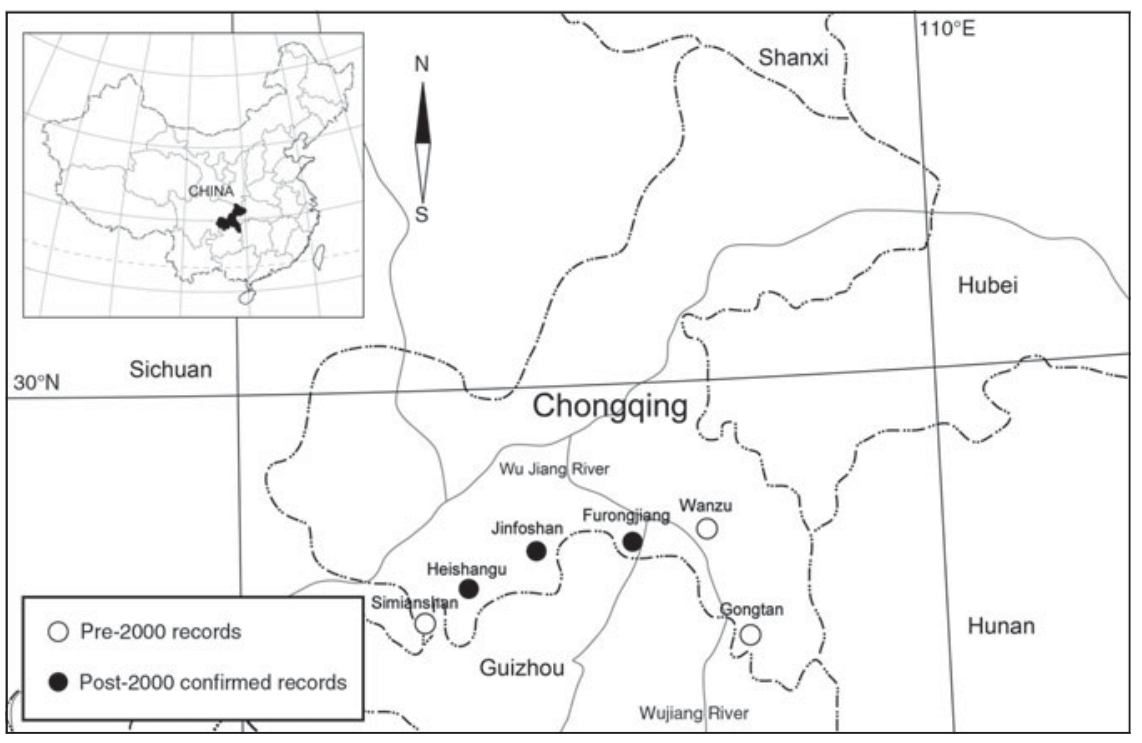

FIG. 1 Distribution of François' langur in southern Chongqing and north-eastern Guizhou. The shading on the inset indicates the location of the main map in China.

TABLE 1 Mean annual temperature and total rainfall of the three survey sites in Chongqing (Fig. 1), with area surveyed and area of occurrence of François' langur Trachypithecus francoisi, and the size of populations and groups and number of survey days, during the three surveys from September 2009 to September 2010.

\begin{tabular}{|c|c|c|c|c|}
\hline & \multicolumn{3}{|l|}{ Site (county) } & \multirow[b]{2}{*}{ Mean/total } \\
\hline & $\begin{array}{l}\text { Jinfoshan } \\
\text { (Nanchuan) }\end{array}$ & $\begin{array}{l}\text { Furongjiang } \\
\text { (Pengshui \& } \\
\text { Wulong) }\end{array}$ & $\begin{array}{l}\text { Heishangu } \\
\text { (Wansheng) }\end{array}$ & \\
\hline $\begin{array}{l}\text { Mean annual } \\
\text { temperature }\left({ }^{\circ} \mathrm{C}\right)\end{array}$ & 12.5 & 17.6 & 18.0 & 17.6 \\
\hline $\begin{array}{l}\text { Mean total annual rainfall } \\
(\mathrm{mm})\end{array}$ & 1,390 & 1,050 & 1,300 & 1,200 \\
\hline Area surveyed $\left(\mathrm{km}^{2}\right)$ & 149.0 & 12.4 & 16.9 & \\
\hline $\begin{array}{l}\text { Area of langur } \\
\text { occurrence, } \mathrm{km}^{2} \\
\text { (altitude range) }\end{array}$ & $50(600-1,520)$ & $3(250-530)$ & $3.5(300-900)$ & \\
\hline \multicolumn{5}{|l|}{ Sep.-Nov. 2009} \\
\hline $\begin{array}{l}\text { Population size } \\
\text { (group sizes) }\end{array}$ & $\begin{array}{c}139(6,11,9,10,5,8,10,6,5 \\
8,2,6,9,7,4,8,8,6,1,10)\end{array}$ & $18(10,8)$ & $7(7)$ & $\begin{array}{l}161 \text { individuals in } 21 \text { mixed sex } \\
\text { groups, } 1 \text { solitary male \& } 1 \text { pair } \\
\text { of young males }\end{array}$ \\
\hline No. of survey days & 42 & 13 & 8 & 63 \\
\hline \multicolumn{5}{|l|}{ Mar.-May 2010} \\
\hline $\begin{array}{l}\text { Population size } \\
\text { (group sizes) }\end{array}$ & $\begin{array}{r}148(6,12,8,6,4,1,1,5,9,10,6 \\
8,7,9,7,4,1,4,9,8,7,10,6)\end{array}$ & $26(12,7,7)$ & $12(7,5)$ & $\begin{array}{l}183 \text { individuals in } 25 \text { mixed sex } \\
\text { groups \& } 3 \text { solitary males }\end{array}$ \\
\hline No. of survey days & 53 & 12 & 11 & 76 \\
\hline \multicolumn{5}{|l|}{ July-Sep. 2010} \\
\hline $\begin{array}{l}\text { Population size } \\
\text { (group sizes) }\end{array}$ & $\begin{array}{r}153(5,12,8,6,4,1,5,9,10,6,5 \\
9,7,9,8,4,4,9,8,7,1,10,6)\end{array}$ & $36(12,9,7,8)$ & $13(8,5)$ & $\begin{array}{l}200 \text { individuals in } 27 \text { mixed sex } \\
\text { groups \& } 2 \text { solitary males }\end{array}$ \\
\hline No. of survey days & 51 & 17 & 12 & 80 \\
\hline Total no. of survey days & 146 & 42 & 31 & 219 \\
\hline $\begin{array}{l}\text { Overall density } \\
\left.\quad \text { (individuals } \mathrm{km}^{-2}\right)\end{array}$ & 3.0 & 12.0 & 3.7 & \\
\hline
\end{tabular}


Systematic surveys using transect-based techniques are not suited to the limestone mountain topography of the François' langur's habitat. We therefore used the methods employed by Hu et al. $(1998,2004)$ and Li et al. (2007) for surveys of langurs in Guangxi. We divided the areas to be surveyed into small units of 1-2 $\mathrm{km}^{2}$. Each was surveyed continuously for 2-3 days by teams of 3-4 people. If no langurs were found the surveyors searched the cliffs for fresh faecal traces (with mucilage or traces with lustre) left by langurs.

When langurs were found we recorded the time of detection and either noted the location with a global positioning system or marked the locality on 1:10,000 maps. We followed the groups for as long as possible to record group size, sex and age composition. We identified age and sex classes based on fur colour, body size and the colour of the sexual skin at the perineum (the female has a white perineum and the male a black one), which can easily be seen when a langur is sitting facing the observer or if it is running $(\mathrm{Hu}, 2007)$. Whilst following the groups we recorded the duration of our observations and data on habitat type, feeding patches and sleeping sites.

The reliability of individual counts in forest depends on the frequency of repeat surveys. From September 2009 to September 2010 we surveyed the three areas during three periods totalling 219 days (Table 1 ). In each period we surveyed each unit at least twice, and three times for units with langur sightings or records of fresh faeces. Surveys normally started at 06.00 and finished at 19.00.

An observation of one langur group on a given day was considered a record. We discarded unclear records (i.e. if the number of individuals was not precisely recorded) and combined duplicated records (records of one langur group by two adjacent survey teams). During each period records of the same langur groups at different times were used for comparison or for revising the data.

Information on hunting, and habitat degradation (cultivated land size, firewood use, tourism facilities and the number of tourists) were collected from records of local governmental agencies and our interviews with 146 local families. When we gathered information on hunting we noted the hunted species, date and location. For information on habitat degradation we recorded the area of cultivated land and amount of firewood used and we collected information on the human population and number of tourists from local governmental agencies.

\section{Results}

\section{Distribution and population}

In the 219 days of surveys we compiled a total of 145 records, of which 13 were unclear and 52 were duplicates, giving 80 unique records of groups and individuals. The detailed results for each of the three survey periods are presented in Table 1. In Jinfoshan we surveyed c. $150 \mathrm{~km}^{2}$ but found langurs only in the core area in the north-east, where most of the vegetation was evergreen broad-leaf forest with some mixed deciduous/coniferous forest. In Furongiiang langurs were found only in the valley bottom, where fragmented broad-leaf forest patches remain along the banks of the river. We found only four langur groups, one in each of four forest patches, isolated from each other by inaccessible cliffs, waterfalls and cultivated land. In Heishangu we found only two groups, in two remnant broad-leaf forest patches in the valley of the Liyu River. Densities were 3.0-12.0 individuals per $\mathrm{km}^{2}$.

\section{Threats}

Hunting of François' langur in these three sites is low, although hunting for other animals (e.g. wild boar, Chinese muntjac Muntiacus muntiak, clouded leopard Neofelis bebulosa and leopard cat Felis bengalensis) does take place occasionally. The main threat to the langurs is habitat loss and degradation in the form of firewood collection, agricultural encroachment and the construction of tourism facilities and hydroelectric power projects, whose effects varied from site to site.

Jinfoshan is a national reserve with many scenic sites; it attracts $>1$ million tourists per year. Over the past decade in this reserve there has been a rapid increase in construction of tourism infrastructure and facilities such as highways, hotels, telephone lines and hydroelectric power installations. Most of this infrastructure was built in an area of natural forest, thus misappropriating or destroying actual or potential habitat. In addition, a new tourism zone is planned in the north-east (L.J. Ma, pers. comm.) in the remains of the primary broad-leaf forest (Plate 1 ) that is the habitat of

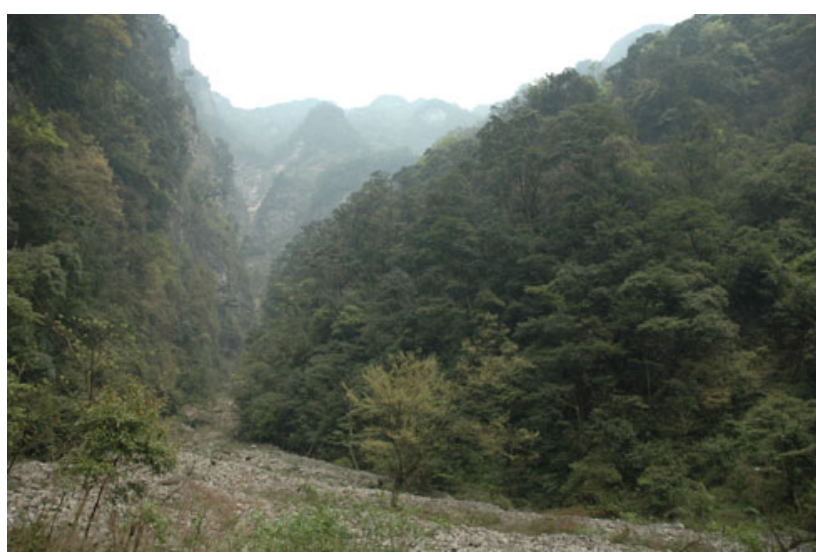

Plate 1 Primary broad-leaf forest in the north-eastern core of Jinfoshan national reserve, Chongqing (Fig. 1). 


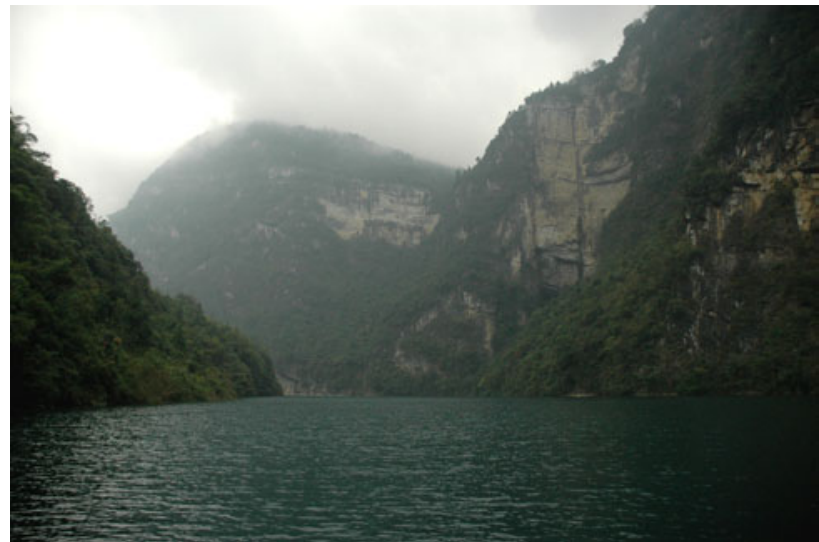

PLATE 2 The riverine broad-leaf forests remaining along the Wujiang river in Furongjiang, Chongqing (Fig. 1).

most of the langur groups. There are c. 8,600 local residents living in villages within or adjacent to the current area of occurrence of the langurs, and the villagers depend largely on the natural forest for wood for cooking and heating and for livestock grazing.

In Furongjiang firewood collection is a continued source of habitat loss. The majority (97\%) of local families collect firewood for cooking and heating; an approximate estimate of consumption is $1,000 \mathrm{~m}^{3}$ per year for all families combined. Almost all suitable flat land and plateaus are cultivated, which restricts the langurs to the forest patches remaining along the two banks of the river. In 2000, when the Jiangkou Hydroelectric Dam was commissioned, the reservoir behind the dam submerged about half of the riverine broad-leaf forests (Plate 2).

In Heishangu primary broad-leaf forest remains only in the north-eastern valley of the Liyu River. Natural forests in other areas of Heishangu have been replaced by forest plantations or farmland (Plate 3) and tourism facilities. The c. 1,100 local families depend mainly on the forest for fuelwood for cooking and heating.

\section{Discussion}

Information from local chronicles indicates that François' langur was formerly widespread in the south and south-east of Chongqing, in seven counties (Jiangjing, Nanchuan, Wansheng, Wulong, Pengshui, Youyang and Xiushan), and our interview data indicated that the species was commonly found in a few sites along the Wujiang River even in the 1980 s. Our survey indicates, however, that the species is now restricted to three isolated sites, with a total population of c. 200 individuals. However, underestimation is a problem that plagues estimates of karst-dwelling primates. Considering the broad historical distribution range, the dissected, steep terrain, the shortness of the preliminary survey and the sites chosen for intensive surveys, it is

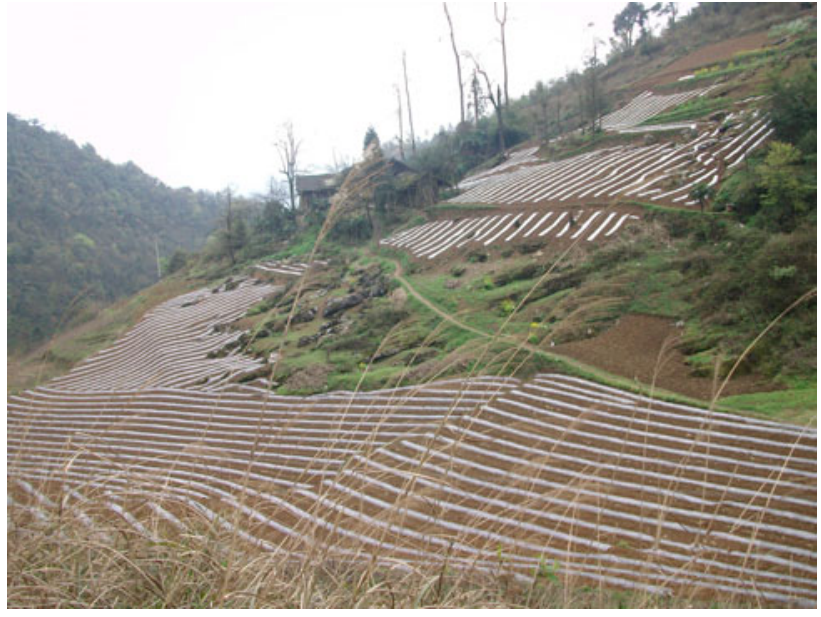

Plate 3 Cultivated land in Heishangu, Chongqing (Fig. 1).

possible that we could have overlooked some langur groups. The data reported here is therefore a minimum estimate of the population and range of the species in Chongqing, and further surveys in other potential sites are needed.

Drastic declines in primate populations in the 2oth century were attributable to the effects of the expanding human population and economic development (Strier, 2000), and the two main threats to primates are hunting and habitat degradation (Marsh et al., 1987). Although hunting has been considered the main cause of the decline of François' langur in Guangxi (Hu et al., 2004; Li et al., 2007), where langurs have been used to make a medicinal wine (Huang et al., 2002; Li et al., 2007), and North Vietnam (Nadler et al., 2003), it is less of a problem in Chongqing because there is no tradition of hunting langurs for commercial purposes. From 1989 to 2009 there were only four cases of poaching in Jinfoshan Reserve (Jinfoshan Reserve Management Bureau, 2010, unpubl. data) and two cases in Furongiiang (Pengshui Police Bureau, 2009, unpubl. data) but none of these were poaching of langurs.

Struhsaker (2005) suggested that, besides hunting, the major threats to red colobus monkeys Piliocolobus tephrosceles are habitat loss, degradation and fragmentation. Habitat degradation is severe and common throughout the range of François' langur (Hu et al., 2004, 2011; Nadler \& Streicher, 2004; $\mathrm{Hu}, 2007$ ). In Chongqing the main causes of habitat loss and degradation were formerly fuelwood collection and encroachment for agriculture but increasingly hydroelectric projects and tourism are having significant effects, and recent increases in the latter have aggravated the effects of habitat degradation. Since 2005 the total number of tourists visiting the three sites surveyed has been c. 2 million per year, of which c. 1.2 million were to Jinfoshan, and 400,000 each to Furongjiang and Heishangu (Chongqing Tourism Bureau, 2010, unpubl. data). There has been an increase in construction of tourism infrastructure and facilities, and consequent loss of forest. Habitat loss and 
degradation may concentrate colobines into smaller patches and aggravate intra- and inter-specific food competition, which may cause a further decline in population viability (Kirkpatrick, 1996), leading to a population crash (Davies, 1994). Although François' langur displays considerable flexibility in feeding and ranging, which helps the species survive and flourish in moderately disturbed habitats $(\mathrm{Hu}$, 2007, 2009), habitat loss and degradation has extirpated the langur from some of its historical range in Guizhou $(\mathrm{Hu}$ et al., 2011).

Although the population of François' langur in Chongqing is only c. 200 in three isolated sites, these areas are adjacent to north-east Guizhou, where there are four sites with c. $60 \%$ of the total wild population of François' langur in China (Hu et al., 2011). The geographical proximity of the sites in Guizhou and Chongqing raises the possibility of setting up ecological corridors between some of them (such as between Jinfoshan and Dashahe; Fig. 1). These seven sites together contain almost $70 \%$ of the total remaining population of François' langur and constitute their last remaining stronghold.

\section{Acknowledgements}

We thank W. Wang and J.L. Ma for their administrative help and for providing data on poaching, Y.Y. Zhang and the Fauna \& Flora International China Programme for their support for this study, the local forestry authorities and all interviewees for their valuable information on the langurs and the number of visiting tourists, C. Chen, H.Q. Li and student volunteers for their help with the survey, Colin Groves, Anthony Di Fiore, Noel Rowe and two anonymous reviewers for their invaluable comments and suggestions, and to L. Liang for drawing the figure. This survey could not have been done without financial support from the ChinaEurope Biodiversity Conservation Project (No. 00060222), the Scientific Research Fund of Chongqing Education Department (No. KJo61304) and the Chongqing Specific Fund for Outstanding Young Scholar.

\section{References}

Bleisch, B., Manh Ha, N., Khat Quyet, L. \& Yongcheng, L. (2008) Trachypithecus francoisi. In IUCN Red List of Threatened Species v. 2012.1. http://www.iucnredlist.org [accessed 19 September 2012].

Davies, A.G. (1994) Colobine population. In Colobine Monkeys: Their Ecology, Behaviour and Evolution (eds A.G. Davies \& J.F. Oates), pp. 285-310. Cambridge University Press, Cambridge, UK.

Fooden, J. (1996) Zoogeography of Vietnamese primates. International Journal of Primatology, 17, 845-899.

Groves, C.P. (2001) Primate Taxonomy. Smithsonian Institution Press, Washington, DC, USA.

HAN, Z.X. \& Hu, J.C. (2010) Food selection by François' langur (Trachypithecus francoisi francoisi) in the spring at Chongqing
Jinfo Mt. National Nature Reserve. Sichuan Journal of Zoology, 29, $857-867$.

Hu, G. (2007) Socioecology and behavioral flexibility of François' langur (Trachypithecus francoisi) in Mayanghe Nature Reserve, southwest China. PhD thesis. The Australian National University, Canberra, Australia.

Hu, G. (2009) Feeding flexibility of wild François' langur at Mayanghe Nature Reserve, and its implications for conservation. In

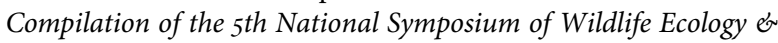
Conservation, pp. 109-110. China Academic Journal Electronic Publishing House, Beijing, China.

Hu, G., Dong, X., Luo, H.Z., Su, X.W., Li, D.Y. \& Zhou, C.Q. (2011) Distribution and population dynamic of François' langur over the past two decades in Guizhou, and the threats towards its survival. Acta Theriologica Sinica, 31, 306-311.

Hu, G., Dong, X., Wei, Y., Zhu, Y. \& Duan, X.H. (2004) Evidence for a decline of François' langur Trachypithecus françoisi in Fusui Nature Reserve, south-west Guangxi, China. Oryx, 38, 48-54.

Hu, G. \& WeI, Y. (2002) Population decline and habitat destruction of François' langur, Trachypithecus françoisi in Fusui Nature Reserve, Southwest Guangxi, China. In Abstracts of the 19th Congress of the International Primatological Society, pp. 74-75. China Academic Journal Electronic Publishing House, Beijing, China.

Hu, G., WEI, Y. \& LI, Z. (1998) The survey on the white-headed langur in Longrei and the analysis of the cause for endangerment. Journal of Guangxi Normal University, 16, 71-75.

Huang, C.M., WeI, F.W., LI, M., Quan, G.Q. \& Li, H.H. (2002) Current status and conservation of white-headed langur (Trachypithecus leucocephalus) in China. Biological Conservation, 104, 221-225.

KirKPATRICK, R.C. (1996) The natural history and conservation of the snub-nosed monkeys (Genus Rhinopithecus). Biological Conservation, 72, 363-369.

LI, M.J. (1995) Ecological study of the tonkin langur (Trachypithecus françoisi) in Guizhou, China. In Primate Research and Conservation (eds W.P. Xia \& R.Z. Zhang), pp. 226-231,. China Forestry Publishing House, Beijing, China.

LI, M.J., LeI, X.P. \& Luo, X.S. (1994) Study on ecology of black leaf monkey in Guizhou Provincial Mayang River Nature Reserve. In Scientific Survey of the Mayang River Black Leaf Monkey Reserve (ed Guizhou Forestry Department), pp. 33-38. Guizhou Nationalities Publishing House, Guiyang, China.

Li, Y.B., Huang, C.M., Ding, P., TANG, Z. \& Wood, C. (2007) Dramatic decline of François's langur Trachypithecus francoisi in Guangxi Province, China. Oryx, 14, 38-43.

LIU, W. \& WEI, Z. (1995) Current status and protection of primates in Guangxi, China. In: Primate Research and Conservation (eds W.P. Xia \& R.Z. Zhang), pp. 123-132. China Forestry Publishing House, Beijing, China.

Marsh, C.W., Johns, A.D. \& Ayres, J.M. (1987) Effects of habitat disturbance on rain forest primates. In: Primate Conservation in the Tropical Rain Forest (eds C.M. Marsh \& R.A. Mittermeier), pp. 83-107. Alan R. Liss, New York, USA.

Nadler, T. \& Streicher, U. (2004) The primates of Vietnam-an overview. In: Conservation of Primates in Vietnam (eds T. Nadler, U. Streicher \& H.T. Long), pp. 5-11. Haki Publishing., Hanoi, Vietnam.

Nadler, T., Momberg, F., Nguyan, X.D. \& Lormee, N. (2003) Vietnam Primate Conservation Status Review. Part two: Leaf Monkeys. Fauna \& Flora International-Vietnam Programme and Frankfurt Zoological Society, Hanoi, Vietnam.

Strier, K.B. (200o) Primate Behavioral Ecology. Allyn and Bacon, Boston, USA. 
STRUhSAKer, T.T. (2005) Conservation of red colobus and their habitat. International Journal of Primatology, 26, 525-538.

Su, H.L., LiN, Y.H. \& MA, Q. (2002) Preliminary survey on population of François' langur (Trachypithecus françoisi françoisi) in Wulong county and Penshui county. Acta Theriologica Sinica, 22, 169-178.

TAnG, H.T. \& ZhAnG, H.Z. (1994) The resource and ecological survey on François' langur. Sichuan Forestry Science and Technology, 15, $48-50$.

TANG, H.T. \& ZhANG, H.Z. (1998) The conservation and utilization of François' langur. Sichuan Forestry Science and Technology, 19, 78-79.

Wu, M.C., WeI, Z.Y. \& HE, N.L. (1987) Distribution and ecology of François' langur in Guangxi. Chinese Wildlife, 12-13, 19.

Zhang, R.Z., Chen, L.W., Xu, W.Y. \& Chris, C. (2002) The Primates of China: Biogeography and Conservation Status. Chinese Forestry Publishing House, Beijing, China.

\section{Biographical sketches}

ZONGXIAN HAN has studied the ecology and conservation of François' langur and other threatened mammals for over 10 years and has participated in several projects in south-west China. GANG HU has studied the behavioural ecology, socioecology and conservation of langurs and other colobines in south-west China for over 15 years. $\mathrm{He}$ currently focuses on the behavioural flexibility of langurs in response to environmental variation and human disturbance, and management planning to minimize conflicts between langurs and local human communities. SH А о вIN Wu studies the ecology and conservation of rare mammal species in Chongqing, including langurs. CHANGLEI $\mathrm{CAO}_{\mathrm{AO}}$ studies the ecology and conservation of rare wildlife and is involved in population surveys and monitoring projects in Chongqing. XIN Dong has research interests in wildlife conservation management, and particularly in habitat quality assessment, monitoring and management. 